
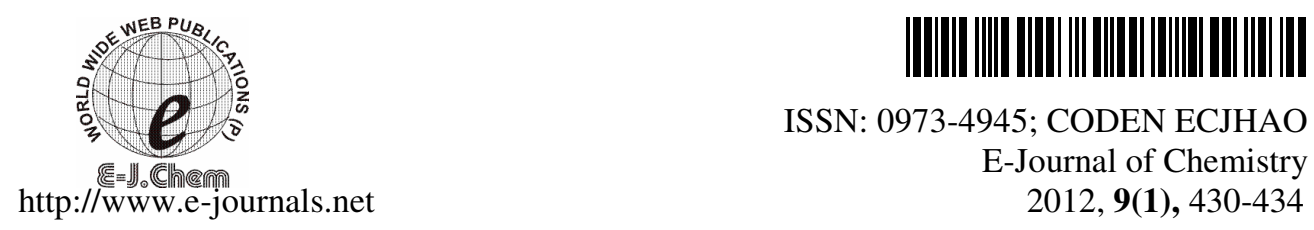

ISSN: 0973-4945; CODEN ECJHAO

E-Journal of Chemistry 2012, 9(1), 430-434

\title{
Kinetics of Vinyl Polymerization of Methyl Methacrylate Initiated by Ce(IV)-Vanillin Redox System
}

\author{
M. PALANIVELU*', K. E. N. NALLA MOHAMED, \\ T. HIDAYATHULLA KHAN and M. PREM NAWAZ \\ P.G and Research Department of Chemistry \\ KhadirMohideen College, Adirampattinam 614 701, Tamilnadu, India \\ nigishpalani@yahoo.in \\ Received 12 October 2011; Accepted 1 December 2011

\begin{abstract}
The kinetics of polymerization of methyl methacrylate initiated by $\mathrm{Ce}(\mathrm{IV})$-Vanillin redox system was studied in aqueous solution of sulfuric acid at $40{ }^{\circ} \mathrm{C}$. The rate of polymerization (Rp) and the reaction orders with respect to monomer, initiator and ligand have been determined and found to be $1.5,0.5$ and 0.5 respectively. The effect of concentration of sulfuric acid on the polymerization was also studied. The rate of polymerization was found to increase with increasing temperature $30-60{ }^{\circ} \mathrm{C}$ and decreases at higher temperature $\left(>60{ }^{\circ} \mathrm{C}\right)$. The overall activation energy (Ea) was found to be $36.7 \mathrm{~kJ} / \mathrm{mol}$. A suitable kinetic scheme has been proposed.
\end{abstract}

Keywords: Kinetics study, Methyl methacrylate, Redox system, Vanillin

\section{Introduction}

Kinetic studies on aqueous polymerization of MMA have been reported ${ }^{1,2}$. Several reports have appeared on the mechanism and kinetics of vinyl polymerization initiated by a variety of initiators ${ }^{3-6}$. Ceric ion has been used in vinyl polymerization in the presence of various organic reducing agents such as alcohols ${ }^{7}, \operatorname{acids}^{8}, \operatorname{amides}^{9}, \operatorname{amines}^{10}$, etc. Rout et al. ${ }^{11}$ have proposed a linear termination step involving interaction of polymer radicals with ceric ion ${ }^{12}$. The redox system involving complex between both an organic substrate and an inorganic salt was already reported ${ }^{13-15}$. A direct oxidation mechanism, without complex formation has been suggested for oxidation in sulfuric $\operatorname{acid}^{16,17}$. This reaction involves the formation of an intermediate complex between the metal ion and the protonated species of the reductant ${ }^{18}$. The literature survey reveals that no systematic investigation of the kinetics of polymerization of MMA with $\mathrm{Ce}$ (IV) and vanillin has been carried out. 


\section{Experimental}

Methyl methacrylate was washed with $5 \% \mathrm{NaOH}$ solution and then with water and dried over calcium chloride. After the drying agent was removed by filtration the monomer was distilled in a nitrogen atmosphere under reduced pressure and stored in a refrigerator ${ }^{15}$. All the reagents used were of Analar grade. Vanillin analytical grade sample was distilled under reduced pressure. Distillated and deionized water were employed in the preparation of the reagents and solutions. The polymerization procedure was as follows: The appropriate quantities of the methyl methacrylate and vanillin were introduced under nitrogen atmosphere. The iodine flasks placed in a thermostated water bath at $40{ }^{\circ} \mathrm{C}$ and then cerium salt was added. The polymerization reactions started almost instantaneously, indicated by the appearance of turbidity that increased with the progress of polymerization, ultimately the polymers precipitated out. After desired intervals the polymerization were halted by adding $2 \mathrm{~mL}$ of ferrous ammonium sulfate. The precipitated polymethyl methacrylate were filtered, washed several times with water and the conversion of MMA was determined by directly weighing the PMMA dried in vacuum at $60{ }^{\circ} \mathrm{C}$. The percentage conversion was obtained from the ratio between the amount of polymer formed and the initial amount of monomer in the mentioned reaction time.

\section{Results and Discussion}

\section{Rate dependence on concentration of monomer}

The effect of monomer concentration on the rate of polymerization was studied by varying concentration of methyl methacrylate (MMA) in the range 1.0 to $5.0 \mathrm{M}$, at fixed concentration of $\mathrm{Ce}(\mathrm{IV})$, Vanillin ( $\mathrm{Vn}$ ) and $\mathrm{H}_{2} \mathrm{SO}_{4}$. The rate of polymerization was found to increase linearly with increasing monomer concentration. The Plot of $\log [\mathrm{MMA}] v s$. $\log R \mathrm{p}$ were linear (slope $=$ $1.504 ; \mathrm{r}^{2}=0.984$ ), (Table 1, Figure 1), thus indicating that the order of reaction is 1.5 with respect to monomer concentration.

Table 1. Dependence of rate on monomer concentration $[\mathrm{Ce}(\mathrm{IV})]=0.0025 \mathrm{M} ;[\mathrm{Vn}]=0.002 \mathrm{M} ;\left[\mathrm{H}^{+}\right]=0.1 \mathrm{M}$; Temp. $40{ }^{\circ} \mathrm{C}$; Time: $60 \mathrm{~min}$

\begin{tabular}{ccccc}
\hline [MMA], mol/L & $2+\log [\mathrm{MMA}]$ & $\mathrm{Rp} \times 10^{6}$ & $6+\operatorname{logRp}$ & \% conversion \\
\hline 0.10 & 1.000 & 4.855 & 0.686 & 2.8 \\
0.15 & 1.176 & 6.866 & 0.837 & 3.9 \\
0.20 & 1.301 & 10.265 & 1.011 & 5.9 \\
0.25 & 1.397 & 14.565 & 1.163 & 8.4 \\
0.30 & 1.477 & 19.768 & 1.296 & 11.4 \\
0.35 & 1.544 & 26.079 & 1.416 & 15.0 \\
0.40 & 1.602 & 32.877 & 1.516 & 18.9 \\
0.45 & 1.653 & 41.755 & 1.621 & 24.0 \\
0.50 & 1.699 & 50.634 & 1.704 & 29.2 \\
\hline
\end{tabular}

Rate dependence on concentration of initiator

The effect of initiator concentration on the rate of polymerization was studied by varying the concentration of the $\mathrm{Ce}(\mathrm{IV})$, in the range of $1.0 \times 10^{-3}$ to $5.0 \times 10^{-3} \mathrm{M}$, at fixed concentration of monomer, ligand and $\mathrm{H}_{2} \mathrm{SO}_{4}$. The rate of polymerization increases with increasing concentration of initiator from $1.0 \times 10^{-3} \mathrm{M}$ to $3.0 \times 10^{-3} \mathrm{M}$. While the concentration of initiator changes from $3.0 \times 10^{-3} \mathrm{M}$ to $5.0 \times 10^{-3} \mathrm{M}$ the rate was found to increases then decrease at higher concentration. The decrease of rate of polymerization at higher [Ce(IV)] can be accounted 
for the oxidation and termination process increases. Similar behavior was also studied by Fernandez and Guzman et al. ${ }^{16}$ in the polymerization of MMA initiated by the redox system.

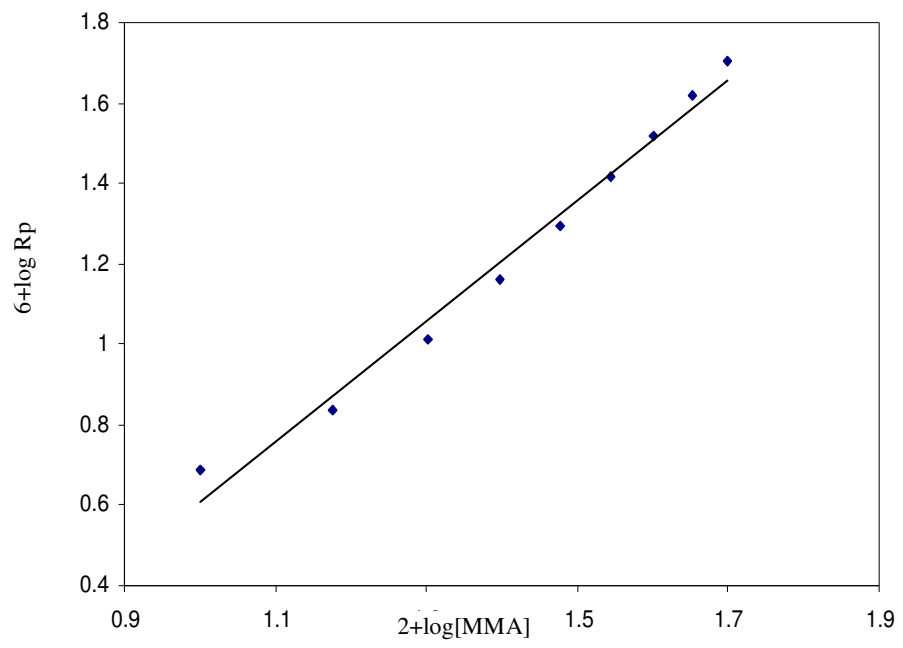

Figure 1. Plot log [MMA]vs.log Rp

\section{Rate dependence on concentration of ligand}

The effect of ligand concentration on the rate of polymerization was studied by varying the concentration of the vanillin $(\mathrm{Vn})$, in the range of $1.0 \times 10^{-3} \mathrm{M}$ to $1.0 \times 10^{-4} \mathrm{M}$, at fixed concentration of monomer, initiator and acid. The rate of polymerization increases with an increase in the $[\mathrm{Vn}]$. The plot of $\log [\mathrm{Vn}] v s . \operatorname{logRp}$ is linear with order of 0.5 (slope $=0.532$; $\mathrm{r}^{2}=0.984$ ) (Table 2; Figure 2).

Table 2. Dependence of rate on Ligand concentration

$[\mathrm{MMA}]=0.25 \mathrm{M} ;[\mathrm{Ce}(\mathrm{IV})]=0.0025 \mathrm{M} ;\left[\mathrm{H}^{+}\right]=0.1 \mathrm{M}$; Temp. $=40{ }^{\circ} \mathrm{C}$; Time: $60 \mathrm{~min}$

\begin{tabular}{ccccc}
\hline$[\mathrm{Vn}] \times 10^{3}, \mathrm{~mol} / \mathrm{L}$ & $3+\log [\mathrm{Vn}]$ & $\mathrm{Rp} \times 10^{6}$ & $6+\operatorname{logRp}$ & \% conversion \\
\hline 1.0 & 1.000 & 10.682 & 1.029 & 6.1 \\
1.5 & 1.176 & 12.832 & 1.108 & 7.4 \\
2.0 & 1.301 & 13.525 & 1.152 & 7.8 \\
2.5 & 1.397 & 14.565 & 1.193 & 8.4 \\
3.0 & 1.477 & 18.380 & 1.264 & 10.6 \\
3.5 & 1.544 & 20.531 & 1.312 & 11.8 \\
4.0 & 1.602 & 21.433 & 1.331 & 13.6 \\
4.5 & 1.653 & 23.583 & 1.373 & 14.0 \\
5.0 & 1.699 & 24.346 & 1.386 & \\
\hline
\end{tabular}

Rate dependence on concentration of acid

The effect on polymer on the addition of acid at different concentration to the polymerization system was studied. It is clear that the addition of sulfuric acid causes a substantial increase in polymerization and at higher concentration of sulfuric acid decreases the rate of polymerization. It is evident that at low acid concentration, the reducing agent may be deprotonated and the coordination becomes easier for the ceric salt whereas at high acid concentration the $\mathrm{Rp}$ is decreases may be due to the high complexation. 


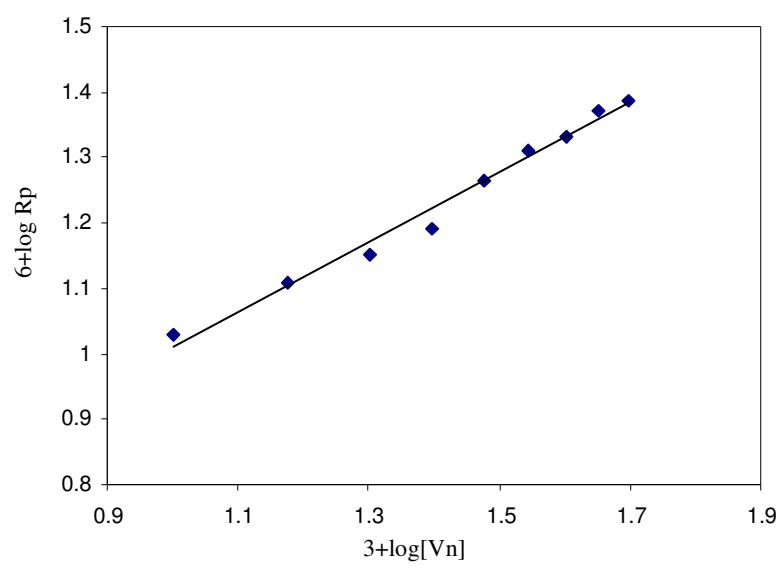

Figure 2. Plot log [Vn] vs. $\log \mathrm{Rp}$

\section{Rate dependence on temperature}

The polymerization was carried out at $30-80{ }^{\circ} \mathrm{C}$ keeping the concentration of all reagents fixed. The rate of polymerization increases with increasing the temperature and the overall activation energy (Ea) for MMA was calculated from the Arrhenius plot. The activation energy is $36.7 \mathrm{~kJ} / \mathrm{mol}$. At above $60{ }^{\circ} \mathrm{C}$ reduction becomes very fast, resulting in a local over concentration of free radicals. Hence the polymer yield decreases.

On the basis of above results and discussion, the following reaction scheme and mechanism is suggested.

Radical formation: $\mathrm{Ce}(\mathrm{IV})+\operatorname{Ligand}(\mathrm{R}) \longleftrightarrow$ Complex $\rightarrow \mathrm{R}^{\circ}+\mathrm{Ce}(\mathrm{III})+\mathrm{H}^{+}$

Initiation:

$$
\mathrm{R}^{\circ}+\mathrm{M} \rightarrow \mathrm{RM}^{\circ}
$$

Propagation:

$$
\mathrm{RM}^{\circ}+\mathrm{M} \rightarrow \mathrm{RMM}^{\circ}
$$

Termination:

$$
2 \mathrm{R}-\mathrm{M}^{\circ} \mathrm{n} \rightarrow \text { Polymer }
$$

The reaction of primary radical $\left(\mathrm{R}^{\circ}\right)$ with $\mathrm{Ce}(\mathrm{IV}): \mathrm{R}^{\circ}+\mathrm{Ce}(\mathrm{IV}) \rightarrow$ Product. Considering the steady-state condition for the polymerization, the following rate expression has been derived.

\section{References}

$$
\mathrm{Rp}=\mathrm{kp}[\mathrm{M}]^{1.5}[\mathrm{Ce}(\mathrm{IV})]^{1 / 2} / \mathrm{kt}^{1 / 2}\left(\mathrm{kK}[\mathrm{R}] /[\mathrm{M}]+\mathrm{k}_{0} / \mathrm{k}_{\mathrm{t}}[\mathrm{Ce}(\mathrm{IV}))^{1 / 2}\right.
$$

1. Fernandez M D and Guzman G M, J Macromol Chem., 1988, 20(1), 91-98.

2. Ananthanarayanan V S and Santappa M, J Appl Polym Sci., 2003, 9, 2437-2449.

3. Sailaja G and Ramachandra Murthy R, Rasayan J Chem., 2010, 3(2), 321- 327.

4. Shanmuga S Sundari and Subbu S, Asian J Chem., 2006, 18(1), 503-508.

5. Patra M and Sinha B K, J Appl Polym Sci., 1997, 64(9), 1825-1834.

6. Rai K S, Sherigara B S and Madegowda N M, Eur Polym J., 2000, 36, 1339- 1345.

7. Manjushree Senapati, Narayan C S, Mishra R, Tripathy B, Swoyam P Rout and Mahendra K, Rout, J Polym Sci., 1983, 21(2), 407- 413.

8. Nagaraja G K and Mahadevaiah Demappa T, J Appl Polym Sci., 2007, 103(6), 3498-3505.

9. Misra G S and Bhattacharya S N, J Polym Chem Ed., 1982, 20, 131-136.

10. Fernandez M D and Guzman G M, Macromol Chem., 1988, 20(1), 91-98. 
11. Rout A, Rout S P, Mallick N, Singh B C and Santappa M, J Polym Ed., 1978, 16, 391-397.

12. Fernandez M D, Pelayo A, Otero T F and Guzman G M, J Polym Sci Polym Lett Ed., 1985, 23(2), 79-83.

13. Erbil C, Cin C, Soydan A B and Sarac A S, J Appl Polym Sci., 1993, 47(9), 16431648.

14. Misra B N and Chandel P S, J Polym Sci., 1977, 15, 1545-1548.

15. Ailton S Gomes and Fernanda M B Coutinho, J Polym Sci Part C: Polym Lett., 1987, 25, 237-241.

16. Fernandez M D, Fernandez M J and Guzman G M, J Polym Sci Part A: Polym Chem., 1989, 27, 3439-3450.

17. Manickam S P, Venkatarao K and Subbaratnam N R, J Polym Sci Polym Chem Ed., 1980, 18, 1679.

18. Misra G S and Arya B D, J Macromol Sci-Chem., 1983, A19(2), 253. 


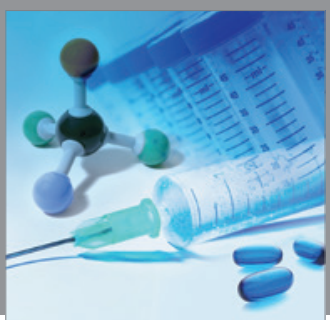

International Journal of

Medicinal Chemistry

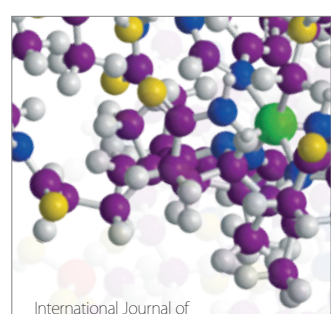

Carbohydrate Chemistry

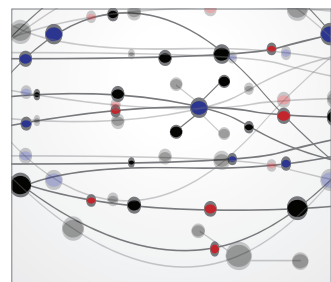

The Scientific World Journal
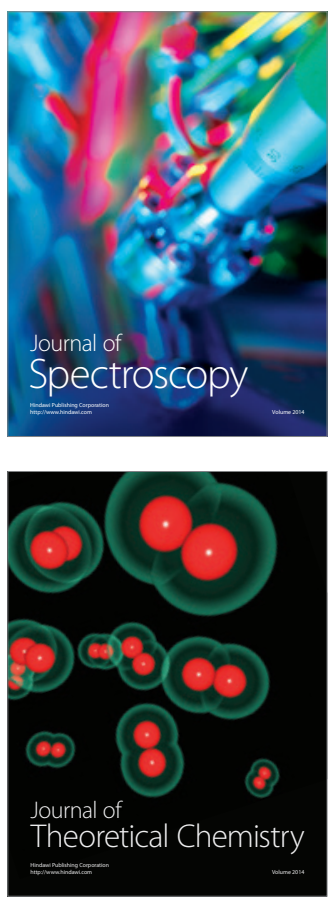
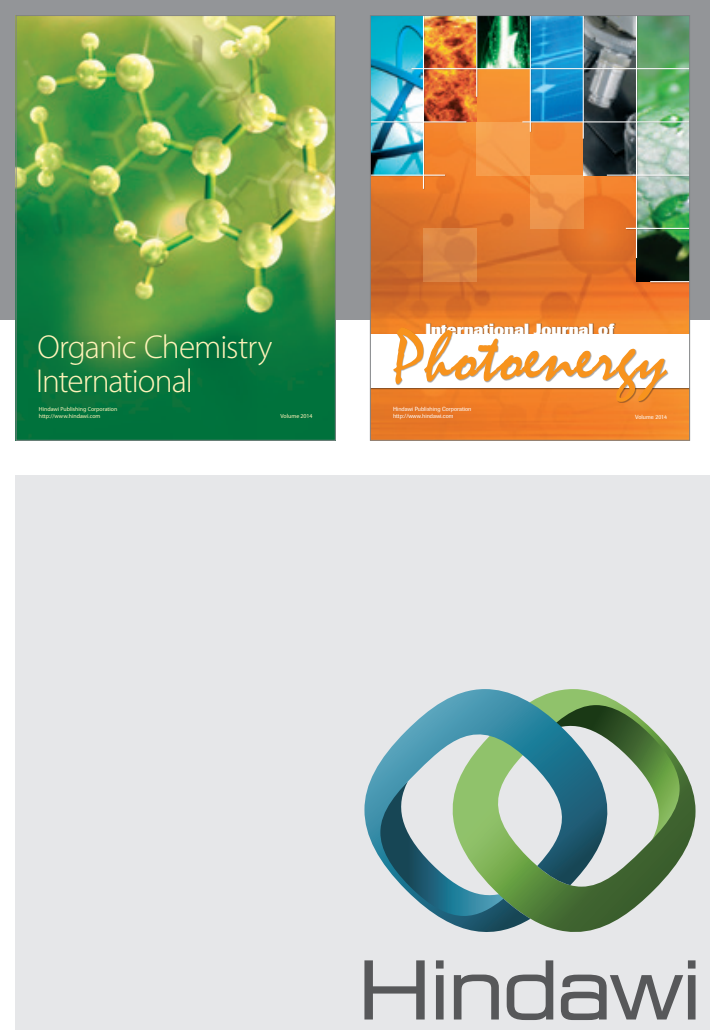

Submit your manuscripts at

http://www.hindawi.com
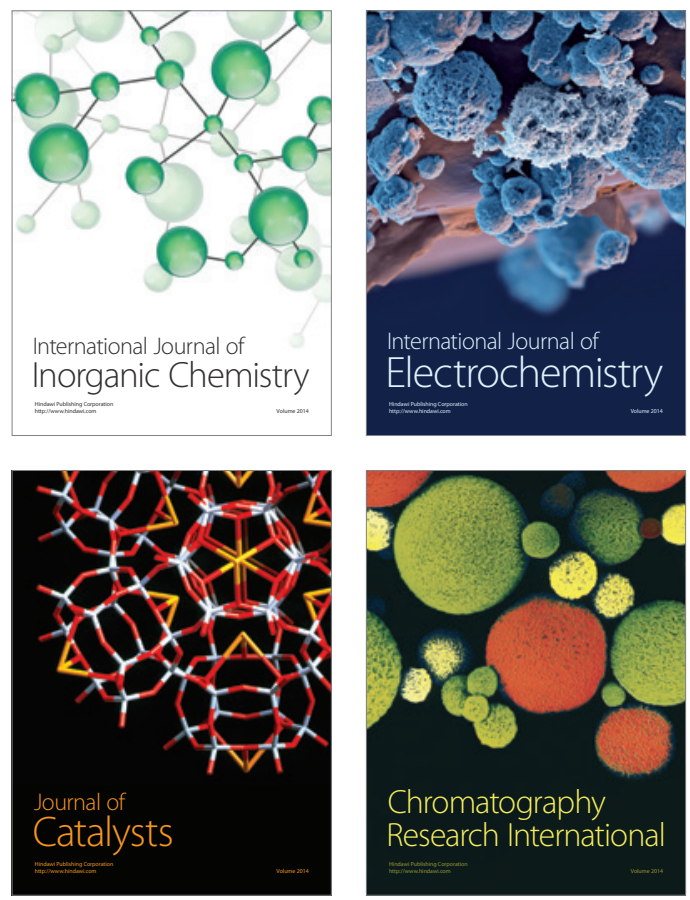
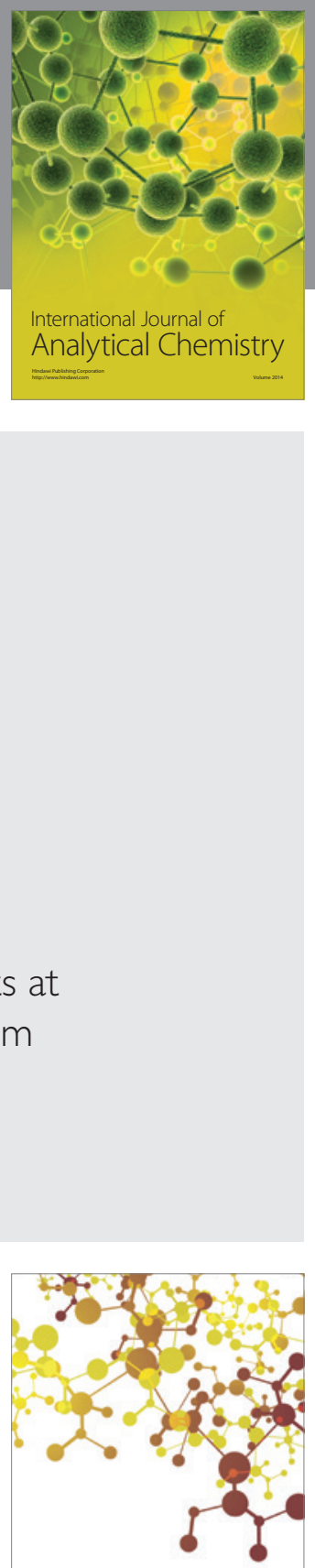

Journal of

Applied Chemistry
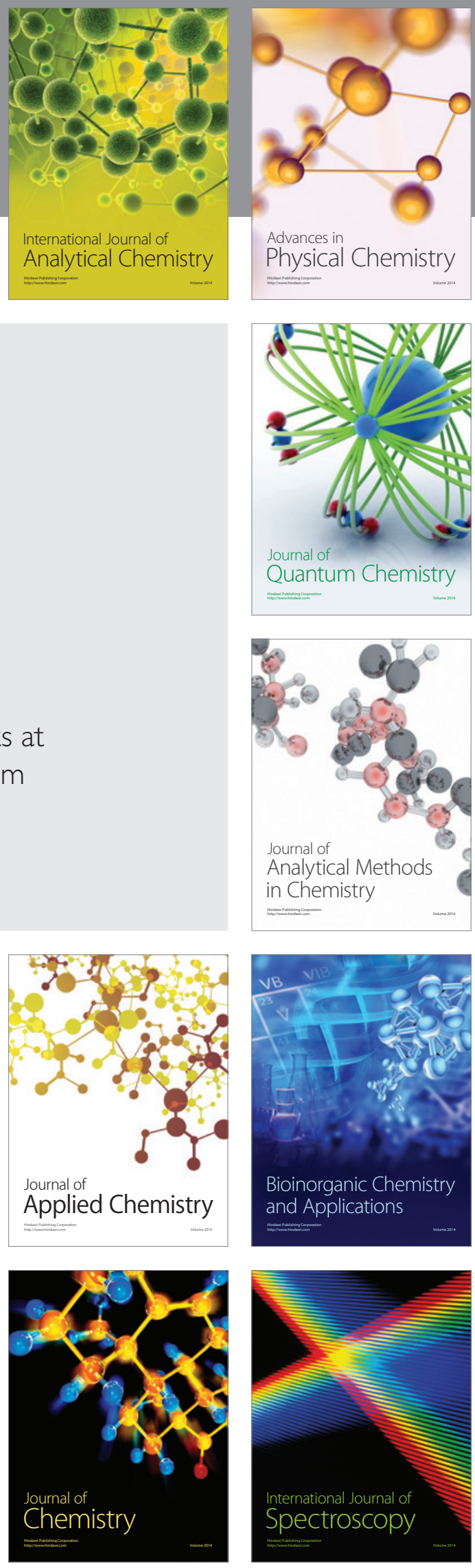